\title{
Relative Analysis of Channel Fading Models in Wireless Networks
}

\author{
N. Priya, P. Nandhini, D.Jeya Priya, Nikita sharma
}

\begin{abstract}
With a specific end goal to enhance and test the framework's viability to oppose blurring, we fundamentally need to display and simulate the correspondence situation under some blurring channel for outlining of a correspondence framework. The trademark of blurring channel is various and complex for various engendering conditions. Accordingly, suitable blurring model for a specific correspondence situation is basic in such manner. Rayleigh blurring and Ricean blurring models are the most commonly utilized little scale models in remote correspondence till date. However, after the appearance of portable radio correspondence, the plan of a situation has been changed to actualize portability of transmitter or beneficiary. Along these lines we have to change the blurring model also. This paper thinks about various blurring models-Rayleigh blurring, Rice a blurring and quick Rayleigh blurring utilizing. The re-enactment comes about demonstrate that Fast Rayleigh Fading model is most appropriate for versatile radio situations which endure thick blurring..
\end{abstract}

Index Terms: Models, Jitter

\section{INTRODUCTION}

In a standout amongst the most well-known cases of remote communication, i.e. versatile correspondence frameworks, the transmitting reception apparatus or Base Station are situated over a pinnacle and emanate at most extreme permitted control. Though, the getting portable station may either be versatile and is available beneath some encompassing building.[1-5] Hence, the channel is influenced by the encompassing structures-autos, structures, and so on. This makes some debasement in the got flag quality. The conduct of any radio channel between a transmitter and a beneficiary can be a because of any of the accompanying marvels: Way misfortune: These misfortunes are because of free-space misfortune, absorption of the transmission medium (i.e. the air) and diffusing of signs themselves when they are discouraged. This way misfortune is normally corrupting with square or forward influence of the separation amongst transmitter and beneficiary. Shadowing: For this situation, the got flag control fluctuates because of substantial items hindering

Revised Manuscript Received on July 22, 2019.

N.Priya, Department of CSE, Bharath Institute of Higher Education and Research, Chennai, Tamilnadu, India.

P. Nandhini Department of CSE, Bharath Institute of Higher Education and Research, Chennai, Tamilnadu, India

D.Jeypriya, Department of CSE, Bharath Institute of Higher Education and Research, Chennai, Tamilnadu, India Higher Education and Research, Chennai, Tamilnadu, India
Nikita Sharma, , Student,Department of CSE, Bharath Institute of

the spread way amongst transmitter and collector. The shadowing impact is typically portrayed by log-ordinary dispersion.

Blurring: Fluctuations in the plentifulness of a radio flag over a brief timeframe or voyaged separate. It is caused by between at least two adaptations of the transmitted signal which touch base at the recipient at somewhat extraordinary circumstances. These waves, called multipath waves, consolidate at the collector radio wire to give a resultant flag which can shift generally in abundance and stage. Marvel of blurring is subdivided as takes after: Huge scale blurring: It comes about because of movement over huge territories. It helps in processing way misfortune as an element of separation. This is regularly portrayed as far as a mean-way misfortune and a log ordinarily circulated variety about the mean.

Little scale blurring: [6-10]It is because of little changes in position. Little scale blurring alludes to changes in flag adequacy and stage which might be because of little changes in the spatial positioning between a beneficiary and a transmitter. Beneath figure gives a graphical portrayal of the previously mentioned blurring wonders. Fig.1. about here.

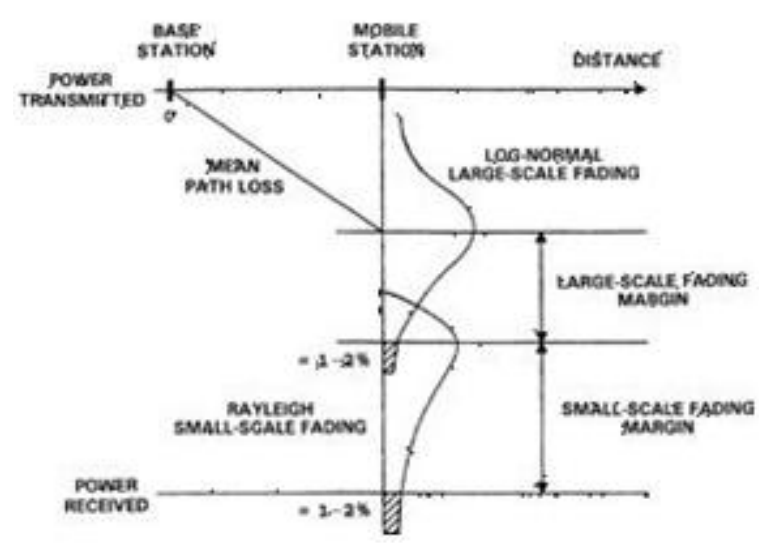

\section{BLURRING MODELS}

Following segment incorporates three summed up blurring models that are fundamentally used to depict little scale blurring.

\section{A Rayleigh Fading Model}

Rayleigh blurring happens when there is no viewable pathway between the transmitter and collector. The blurring speed is influenced by how quick the collector as well as transmitter or the encompassing objects are

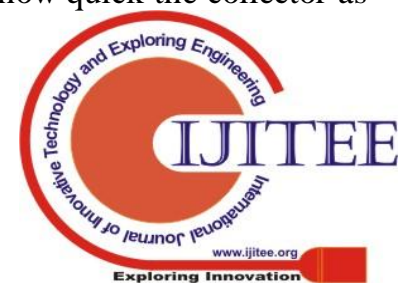


moving. Pdf of Rayleigh Fading Distribution[11-15].

A normal Rayleigh blurring envelope at $900 \mathrm{MHz}$ is appeared in fig. 2. The transporter beneficiary speed here is $120 \mathrm{Km} / \mathrm{hr}$

\section{B. Ricean Fading Model}

In little scale blurring, when the flag touches base at the collector by a few ways and one of them, ordinarily an observable pathway (LOS) flag is substantially more grounded than the others, at that point such channel is named as Ricean Fading Channel and the amplitude of got flag is said to be Rice Distributed. Fig.2. about here.

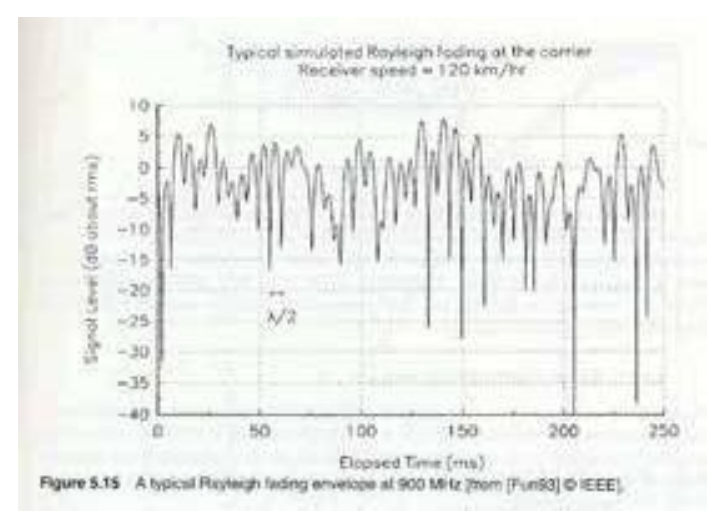

\section{Quick Rayleigh Fading Model}

This model is utilized for systems where either the transmitter or beneficiary is versatile with high speed, at that point the prevailing fashioning gets serious and how quickly the channel blurs, will be influenced by how quick they are moving. Because of relative motion between the transmitter and the beneficiary, each multipath wave encounters clear move in the recurrence. This move in the got flag recurrence is called as Doppler's work day. In such a situation, little scale blurring itself is ordered as Time-Variance[16-20] of channel and Time-Spreading of.The terms moderate and quick blurring allude to the rate at which size and stage change forced by the channel on the flag changes.

Moderate blurring emerges when the intelligibility time of the channel is vast in respect to the postpone requirement of the channel. Quick prevailing fashioning happens when the adequacy and stage change forced by the channel shifts and isn't steady. It happens when the lucidness time of the channel is little with respect to postpone constraint of the channel

For all intents and purposes, it has been seen that, such a trademark is noticed in particular, exceptionally thick and profoundly dispersive regions. In most progressive systems like Wireless Sensor Networks, the blurring impact is significantly more serious and such a blurring is then displayed utilizing Hyper-Rayleigh Fading Model.

\section{RECREATION ENVIRONMENT}

This segment gives the points of interest of the recreation condition used to reproduce the outcomes and depiction of parameters set.

Here, a situation is made that comprises of 7 hubs, out of which node1 is the PAN facilitator (Full Function Device) while the other three, node2 to 7 are transmitters (Reduced Function Devices). Presently, we have connected distinctive blurring models in this situation. [21-25]A preview of the same is given be-low. Fig.5. about here.

\section{RESULTS}

Based on the above recreation, following outcomes are accomplished with few application layer parameters, in type of visual charts.

\section{A. Average Jitter}

Jitter is utilized as a measure of the inconstancy after some time of the parcel inactivity over a system.Along these lines, jitter in any correspondence situation ought to be minimum. Presently since the situation taken here is very blurred (WSN or some other profoundly thick system) it will endure high jitter. In this way, among all the three accessible blurring models-Rayleigh, Ricean, Fast Rayleigh, Fast Rayleigh gives most extreme jitter be-cause Fast Rayleigh can model such systems in the most ideal way. So it precisely measures the impact of blurring than Rayleigh or Ricean models.

\section{B. Add up to Packets Received}

This diagram demonstrates that amid transmission, out of all transmit-ted bundles just a sum of 14 parcels could reach in Rayleigh and Ricean display. Be that as it may, if there should arise an occurrence of Fast Rayleigh demonstrate, 57 parcels came to. This demonstrates Fast[26-30] Rayleigh display has preferred execution over different models.

\section{Normal end to end Delay}

Normal end-to-end postpone alludes to the time taken for a bundle to be transmitted over a system from source to goal. For any system, it ought to be as low as could reasonably be expected. Quick Rayleigh Model shows less end-to-end defer an incentive than the other two models. In this way we can state that Fast Rayleigh demonstrate[31-35] adjust extreme blurring situations better that the other two models.

\section{Throughput}

Throughput is the normal rate of fruitful message de-uniform over a correspondence channel. Subsequently, in any net-work, throughput ought to be high. In the reproduced situation, add up to enter throughput was 2500 
bits/sec.[36-40]Be that as it may, because of the impact of blurring, the parcels endured misfortune and the general throughput is diminished. Here since the displayed situation is exceptionally inclined to blurring, it is best demonstrated by Fast Rayleigh Model than Rayleigh or Ricean models giving maxi-mum throughput estimation of 3200 bits/sec nearly[41,42]..

\section{CONCLUSION}

On the premise on above outcomes, following conclusions can be drawn.

I. Since the situation comprises of 7 hubs set in close region. This speaks to principally a thick situation.

II. Application layer parameters-jitter, add up to parcels received, end to end defer and throughput demonstrates optimum esteems for quick Rayleigh display as it were.

III. This implies, out of all the three blurring models, quick Rayleigh blurring model shows preferred outcomes over the other two. Thus, we can state that quick Rayleigh blurring is best suited for such thick systems.

\section{REFERENCES}

[1] Kumaravel A., Rangarajan K.,Algorithm for automaton specification for exploring dynamic labyrinths,Indian Journal of Science and Technology,V-6,I-SUPPL5,PP-4554-4559,Y-2013

[2] P. Kavitha, S. Prabakaran "A Novel Hybrid Segmentation Method with Particle Swarm Optimization and Fuzzy C-Mean Based On Partitioning the Image for Detecting Lung Cancer" International Journal of Engineering and Advanced Technology (IJEAT) ISSN: 2249-8958, Volume-8 Issue-5, June 2019

[3] Kumaravel A., Meetei O.N.,An application of non-uniform cellular automata for efficient cryptography,2013 IEEE Conference on Information and Communication Technologies, ICT 2013,V-,I-,PP-1200-1205,Y-2013

[4] Kumarave A., Rangarajan K.,Routing alogrithm over semi-regular tessellations, 2013 IEEE Conference on Information and Communication Technologies, ICT 2013,V-,I-,PP-1180-1184,Y-2013

[5] P. Kavitha, S. Prabakaran "Designing a Feature Vector for Statistical Texture Analysis of Brain Tumor" International Journal of Engineering and Advanced Technology (IJEAT) ISSN: 2249-8958, Volume-8 Issue-5, June 2019

[6] Dutta P., Kumaravel A.,A novel approach to trust based identification of leaders in social networks,Indian Journal of Science and Technology,V-9,I-10,PP--,Y-2016

[7] Kumaravel A., Dutta P.,Application of Pca for context selection for collaborative filtering,Middle - East Journal of Scientific Research,V-20,I-1,PP-88-93,Y-2014

[8] Kumaravel A., Rangarajan K.,Constructing an automaton for exploring dynamic labyrinths,2012 International Conference on Radar, Communication and Computing, ICRCC 2012,V-,I-,PP-161-165,Y-2012

[9] P. Kavitha, S. Prabakaran "Adaptive Bilateral Filter for Multi-Resolution in Brain Tumor Recognition" International Journal of Innovative Technology and Exploring Engineering (IJITEE) ISSN: 2278-3075, Volume-8 Issue-8 June, 2019

[10] Kumaravel A.,Comparison of two multi-classification approaches for detecting network attacks, World Applied Sciences Journal,V-27,I-11,PP-1461-1465,Y-2013

[11] Tariq J., Kumaravel A.,Construction of cellular automata over hexagonal and triangular tessellations for path planning of multi-robots,2016 IEEE International Conference on Computational Intelligence and Computing Research, ICCIC 2016,V-,I-,PP--,Y-2017

[12] Sudha M., Kumaravel A.,Analysis and measurement of wave guides using poisson method,Indonesian Journal of Electrical Engineering and Computer Science, V-8,I-2,PP-546-548, Y-2017

[13] Ayyappan G., Nalini C., Kumaravel A.,Various approaches of knowledge transfer in academic social network,International

Journal

of

Engineering

and

[14] Kaliyamurthie, K.P., Sivaraman, K., Ramesh, S. Imposing

patient data privacy in wireless medical sensor networks through homomorphic cryptosystems 2016, Journal of Chemical and Pharmaceutical Sciences 92.

[15] Kaliyamurthie, K.P., Balasubramanian, P.C. An approach to multi secure to historical malformed documents using integer ripple transfiguration 2016 Journal of Chemical and Pharmaceutical Sciences 92.

[16] A.Sangeetha,C.Nalini,"Semantic Ranking based on keywords extractions in the web", International Journal of Engineering \& Technology, 7 (2.6) (2018) 290-292

[17] S.V.GayathiriDevi,C.Nalini,N.Kumar,"An efficient software verification using multi-layered software verification tool "International Journal of Engineering \& Technology, 7(2.21)2018 454-457

[18] C.Nalini,ShwtambariKharabe,"A Comparative Study On Different Techniques Used For Finger - Vein Authentication", International Journal Of Pure And Applied Mathematics, Volume 116 No. 8 2017, 327-333, Issn: 1314-3395

[19] M.S. Vivekanandan and Dr. C. Rajabhushanam, "Enabling Privacy Protection and Content Assurance in Geo-Social Networks", International Journal of Innovative Research in Management, Engineering and Technology, Vol 3, Issue 4, pp. 49-55, April 2018.

[20] Dr. C. Rajabhushanam, V. Karthik, and G. Vivek, "Elasticity in Cloud Computing”, International Journal of Innovative Research in Management, Engineering and Technology, Vol 3, Issue 4, pp. 104-111, April 2018

[21] K. Rangaswamy and Dr. C. Rajabhushanamc, "CCN-Based Congestion Control Mechanism In Dynamic Networks", International Journal of Innovative Research in Management, Engineering and Technology, Vol 3, Issue 4, pp. 117-119, April 2018.

[22] Kavitha, R., Nedunchelian, R., "Domain-specific Search engine optimization using healthcare ontology and a neural network backpropagation approach", 2017, Research Journal of Biotechnology, Special Issue 2:157-166

[23] Kavitha, G., Kavitha, R., “An analysis to improve throughput of high-power hubs in mobile ad hoc network" , 2016, Journal of Chemical and Pharmaceutical Sciences, Vol-9, Issue-2: 361-363

[24] Kavitha, G., Kavitha, R., "Dipping interference to supplement throughput in MANET" , 2016, Journal of Chemical and Pharmaceutical Sciences, Vol-9, Issue-2: 357-360

[25] Michael, G., Chandrasekar, A.,'Leader election based malicious detection and response system in MANET using mechanism design approach", Journal of Chemical and Pharmaceutical Sciences(JCPS) Volume 9 Issue 2, April - June 2016.

[26] Michael, G., Chandrasekar, A.,"Modeling of detection of camouflaging worm using epidemic dynamic model and power spectral density", Journal of Chemical and Pharmaceutical Sciences(JCPS) Volume 9 Issue 2, April - June 2016.

[27] Pothumani, S., Sriram, M., Sridhar, J., Arul Selvan, G., Secure mobile agents communication on intranet,Journal of Chemical and Pharmaceutical Sciences, volume 9, Issue 3, Pg No S32-S35, 2016

[28] Pothumani, S., Sriram, M., Sridhar, Various schemes for database encryption-a survey, Journal of Chemical and Pharmaceutical Sciences, volume 9, Issue 3, Pg NoS103-S106, 2016

[29] Pothumani, S., Sriram, M., Sridhar, A novel economic framework for cloud and grid computing, Journal of Chemical and Pharmaceutical Sciences, volume 9, Issue 3, Pg No S29-S31, 2016

[30] Priya, N., Sridhar, J., Sriram, M. "Ecommerce Transaction Security Challenges and Prevention Methods- New Approach" 2016 ,Journal of Chemical and Pharmaceutical Sciences, JCPS Volume 9 Issue 3.page no:S66-S68

[31] Priya, N.,Sridhar,J.,Sriram, M."Vehicular cloud computing security issues and solutions" Journal of Chemical and Pharmaceutical Sciences(JCPS) Volume 9 Issue 2, April - June 2016

[32] Priya, N., Sridhar, J., Sriram, M. "Mobile large data storage security in cloud computing environment-a new approach" JCPS Volume 9

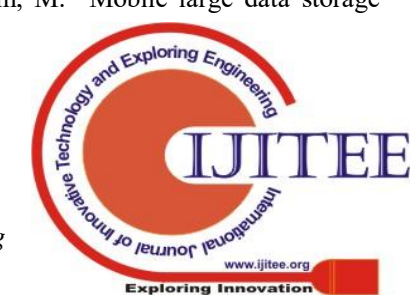




\section{Relative Analysis of Channel Fading Models In Wireless Networks}

Issue 2. April - June 2016

[33] Anuradha.C, Khanna.V, "Improving network performance and security in WSN using decentralized hypothesis testing "Journal of Chemical and Pharmaceutical Sciences(JCPS) Volume 9 Issue 2, April - June 2016

[34] Anuradha.C, Khanna.V, "A novel gsm based control for e-devices" Journal of Chemical and Pharmaceutical Sciences(JCPS) Volume 9 Issue 2, April - June 2016.

[35] Anuradha.C, Khanna.V, "Secured privacy preserving sharing and data integration in mobile web environments " Journal of Chemical and Pharmaceutical Sciences(JCPS) Volume 9 Issue 2, April - June 2016

[36] Sundarraj, B., Kaliyamurthie, K.P. Social network analysis for decisive the ultimate classification from the ensemble to boost accuracy rates 2016 International Journal of Pharmacy and Technology 8

[37] Sundarraj, B., Kaliyamurthie, K.P. A content-based spam filtering approach victimisation artificial neural networks 2016 International Journal of Pharmacy and Technology 83.

[38] Sundarraj, B., Kaliyamurthie, K.P. Remote sensing imaging for satellite image segmentation 2016 International Journal of Pharmacy and Technology 83 .

[39] Sivaraman, K., Senthil, M. Intuitive driver proxy control using artificial intelligence 2016 International Journal of Pharmacy and Technology 84.

[40] Sivaraman, K., Kaliyamurthie, K.P. Cloud computing in mobile technology 2016 Journal of Chemical and Pharmaceutical Sciences 92.

[42] Sivaraman, K., Khanna, V. Implementation of an extension for browser to detect vulnerable elements on web pages and avoid click jacking 2016 Journal of Chemical and Pharmaceutical Sciences 92.

\section{AUTHORS PROFILE}

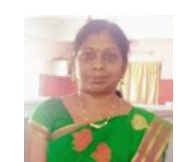

N.Priya Assistant Professor, Department of Computer Science \& Engineering, Bharath Institute of Higher Education and Research, Chennai, India

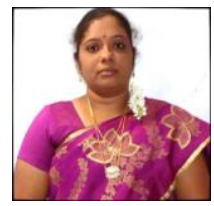

P.Nandhini, Assistant Professor, Department of Computer Science \& Engineering, Bharath Institute of Higher Education and Research, Chennai, India

D.Jeyapriya, Assistant Professor, Department of Computer Science \& Engineering, Bharath Institute of Higher Education and Research, Chennai, India

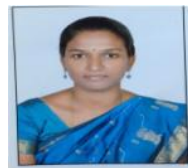

Nikita Sharma, Student, Department of Computer Science \& Engineering, Bharath Institute of Higher Education and Research, Chennai, India 